\title{
To Shave or Not to Shave?
}

\section{How Beardedness in a Linkedin Profile Picture Influences Perceived Expertise and Job Interview Prospects}

\author{
Sarah van der Land ${ }^{1}$ and Daan G. Muntinga ${ }^{2}$ \\ ${ }^{1}$ Erasmus University Rotterdam, The Netherlands \\ ${ }^{2}$ University of Amsterdam, The Netherlands \\ vanderlandeeshcc.eur.nl
}

\begin{abstract}
This study explores whether wearing a beard in a LinkedIn profile picture affects a candidate's prospects of being invited for a job interview and whether this is contingent on the type of job vacancy. Based on Ohanian's (1990) three sub dimensions of credibility, three different job vacancies were constructed: (1) architect for an expertise-job, (2) back cashier officer for a trustworthiness-job, and (3) sales representative for an attractiveness-job. Results of a 2 (candidate: beard versus no beard) x 3 (job type: expertise, trustworthiness, attractiveness) experiment conducted among 216 participants show that bearded candidates are perceived as having more expertise than cleanshaven candidates. Moreover, a candidate's perceived expertise is a significant predictor of the intention to invite the candidate for a job interview. Theoretical and practical implications of these findings are discussed.
\end{abstract}

Keywords: Personal Branding, Strategic Social Media, recruitment, beards, credibility, job interview success, LinkedIN.

\section{Introduction}

As a sign of fashionable masculinity, the male facial beard has risen and fallen regularly throughout history. Quite consistently, however, it has been associated with divine and political authority [11]. Hence, many kings grew beards and often had themselves portrayed wearing one, in order to emphasize their power and reigning expertise.

As evidenced by the many European monarchs currently growing a beard, kings are among the many professionals that are well aware of the fact that visual cues are essential in forming impressions of others [7]. A strong first impression, in particular, is vital in the context of job recruitment [3]. Today's employers are increasingly using Social Network Sites (SNSs; e.g., Facebook and LinkedIn) to screen potential job applicants before inviting them to a job interview [13]. Based on minimal visual cues for online self-presentation (e.g., a candidate's profile picture or affiliations), employers judge a candidate's personality and intelligence without ever meeting him/her [13]. Thus, the cues a potential job candidate displays on their online profile may determine interpersonal impression formation and, evidently, job interview success. 
This study therefore explores whether one specifically salient visual cue in a LinkedIn profile picture, namely wearing a beard, affects a candidate's prospects of being invited for a job interview, and whether this is contingent on the type of job vacancy. This study builds on prior work by Guido, Peluso, and Moffa (2011) on the effects of bearded endorsers in advertising, and extends their research design to the context of job recruitment. In the next section, the theoretical rationale for our hypotheses is provided. Subsequently, the methodology used to empirically test our hypotheses is described. In the fourth section, the results are presented. Finally, we discuss the theoretical and practical implications of this study.

\section{Theoretical Framework}

Because recruiters have limited time and information processing capabilities to search among the online pool of potential job candidates on LinkedIN [13], they must resort to heuristic inferential strategies to economize their judgments [19]. Therefore, their judgments are likely to be guided by peripheral cues displayed on a profile picture such as gender, ethnicity, glasses, and facial hair. Online, such simple cues may magnify the effects of impression formation [24]. According to research in the field of impression formation, one specifically relevant cue is facial hair [20]. Colloquial evidence suggests that there is a negative correlation between professional success and facial hair [24]. Therefore, this study focuses on the role of beardedness as a cue, which refers to the presence (or absence) of a well-groomed beard on a job candidate's face.

Throughout history studies have shown that beards have been associated with positive personality traits such as maturity [3], intelligence, courage, sincerity, composure, and competence [20, 23, 4]. However, in terms of attractiveness, some research suggests that bearded men are perceived to be less attractive than those who are clean-shaven [17, 5], while other studies, have indicated differently. Barber (2001) for instance, from a biological standpoint suggests that wearing a beard makes men more attractive because they "are seen as having the biological and social qualities that would enhance their value as husbands" (p. 262).

Based on Guido et al.'s (2011) research on the effects of bearded endorsers in advertising, Johnston's (2011) exploration of beards' socio-cultural meaning, Dixson and Brooks' (2013) recent study of the evolutionary function of beardedness, and Reed and Blunk's (1990) finding that bearded men are more competent than cleanshaven men, we hypothesize the following:

H1: A candidate who is displayed wearing a beard in his LinkedIn profile picture is perceived more as an expert than a candidate who is displayed without a beard.

In the context of persuasive communication, higher levels of perceived expertise have been linked to attitude change and consumer purchase behavior $[18,26]$. For example, Woodside and Davenport (1974) found that salesmen who were perceived as an expert were able to gain a significantly higher number of customer purchases for their product than salesmen who were not perceived as such. In a similar vein, we therefore argue that the perceived expertise of job candidate will affect the intentions to invite him for a job interview and offer the following hypothesis: 
$\mathrm{H} 2$ : The more a candidate is perceived as an expert, the more likely he is to be invited for a job interview.

Beardedness increases a candidate's perceived credibility, and could prompt the likeliness of recruiters to invite the candidate for an interview, especially when the attributes of the candidate's personality are congruent with the available job. Based on the match-up hypothesis $[12,16]$ and Guido et al.'s (2011) prior work, we argue that for jobs associated with expertise (e.g., an architect), men with beards elicit a higher level expertise which could positively influence a recruiter's perception of a bearded candidate's suitability for the job than a clean-shaven candidate. This effect would not occur for attractiveness-jobs or trustworthiness-jobs, as the incongruence between the image of the bearded candidate with the attributes related to the job could inhibit job interview success. Therefore the following hypothesis is presented:

H3: Wearing a beard on a LinkedIn profile picture positively affects expertise perceptions, which in turn increases the likeliness to be invited for a job interview, but only for expertise-jobs.

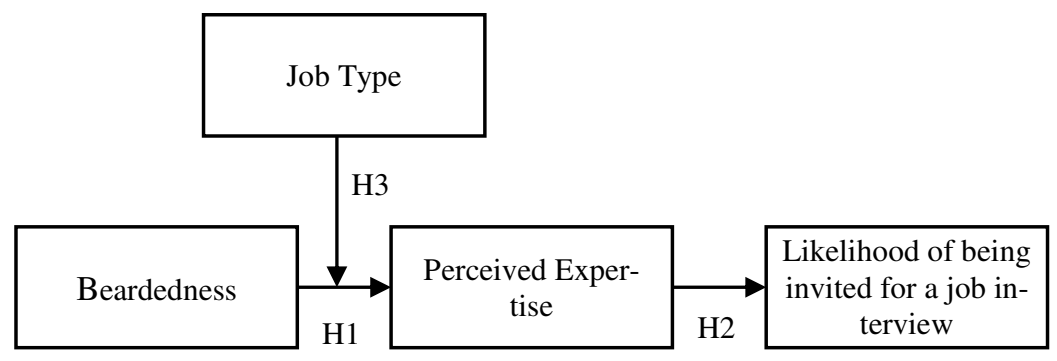

Fig. 1. Conceptual model of this study

\section{$3 \quad$ Method}

To test these hypotheses graphically displayed in Figure 1, a 2 (candidate: beard versus no beard) x 3 (job type: attractiveness, trustworthiness, expertise) between subject factorial design was conducted.

\subsection{Sample}

This study was carried out among a convenience sample of 216 adults between 18 and 69 years old $(53.2 \%$ female, Mage $=29.01, \mathrm{SD}=10.81)$. Participants were recruited via the social networks of the students who participated in a Master's level Communication Science course at a high-ranked University in the Netherlands. Of these participants, $27.6 \%$ indicated using LinkedIN at least once a week.

\subsection{Research Design}

Three job vacancies were established to represent Ohanian's (1990) three sub-dimensions of credibility: attractiveness, trustworthiness, and expertise. The corresponding types of 
job vacancies were determined by a focus group of fifteen university students consisting of thirteen women and two men. It was determined that the attractiveness job vacancy should be represented by a sales person at a fashion store, the trustworthiness job vacancy by a back office bank cashier, and the expertise job vacancy by an architect. The job vacancy descriptions were based on existing online job postings for similar vacancies. A manipulation check was performed to check whether each job represented the correct sub-dimension of credibility. For the manipulation check, eleven participants were asked to give the three most important qualities needed in a candidate for each of the three job categories. Their answers verified that each job vacancy was a valid representation of the intended sub-dimension. Appendix A shows the final job vacancies.

In terms of facial stimuli, beardedness in this study constitutes of a well-groomed beard, since research has shown that employers consider grooming one of the most important physical factors of candidates' suitability for the job [21]. A relatively young male (30 years of age) was chosen as a model, because candidates in this age category are rewarded more positive replies to their job application by recruiters than older candidates [10]. The model wore a black shirt because employers prefer candidates to wear dark, conservative clothing during job interviews [21]. The model expressed a neutral face, in order to avoid unwanted interpersonal effects of smiling [15].

In this study, beardedness is a dichotomous rather than a continuous variable: in the first condition a beard was present, and in the second condition the model was clean-shaven. To ensure that the beard was the only manipulation cue, the picture of the model was photoshopped by a graphical designer, creating two identical pictures in terms of facial expression. Thus, apart from this manipulation, these two LinkedIn profile pictures were identical. To determine whether the photoshopped facial stimuli for the experiment were realistic, three judges rated the picture of which the results were confirmed satisfactorily. Finally, the LinkedIN logo was added to increase the photo's likeness to a real LinkedIN profile picture (see Figure 2).

\section{Linked in.}

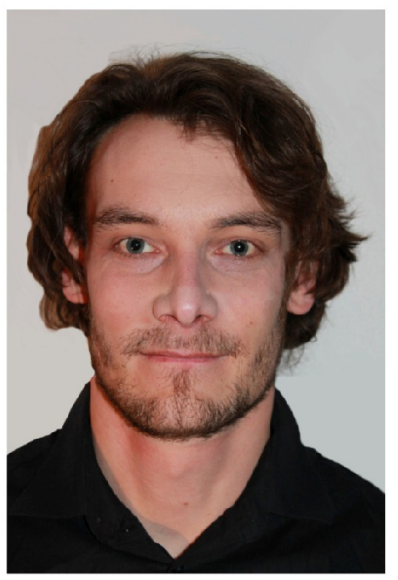

\section{Linkedin.}

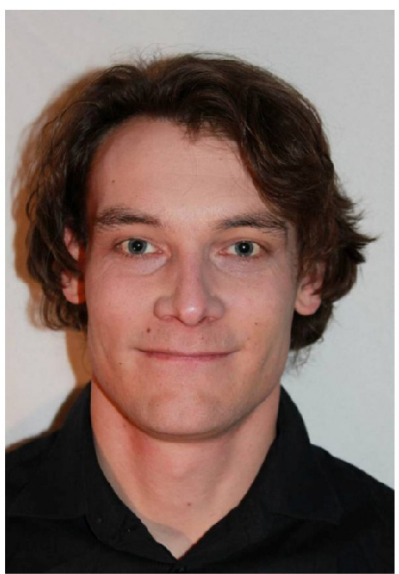

Fig. 2. Facial Stimuli 


\subsection{Procedure}

Respondents were led to a Qualtrics survey website after having clicked on the online link. The first page of the survey presented a short overview of the purpose of the study and background of the researchers. Subsequently, the respondents were randomly assigned to one of the six experimental conditions (e.g. with beard versus without beard in combination with one of the three designed jobs). Respondents were forced to look at the job description for at least 20 seconds first (a timer only activated the "next" button after 20 seconds) and at least ten seconds at the LinkedIn profile picture, after which the post experiment questionnaire was activated.

\subsection{Measures}

The post experiment questionnaire used Ohanian's (1990) seven-point semantic differential scale to measure the perceived credibility of the candidate. The scale consisted of fifteen items, five for each of the three sub-dimensions. The scales for attractiveness, trustworthiness, and expertise were all shown to be sufficiently reliable (Cronbach's alpha $=.81,=.91$, and $=.90$ respectively). To measure the intention to invite the candidate for a job interview, a two-item rating scale was adopted from Fishbein and Ajzen (1975). One item measured the strength of the likeliness to invite the job candidate ("If you were a recruiter, how likely is it that you would invite this person to a job interview?"); the second item measured the subjective probability that the inviting behavior would be effectively performed within the next three months ("If a vacancy opens in your office in the next three months, would you invite this candidate for a job interview?"). Both questions were answered using a seven-point Likert scale ranging from 1 (not very likely) to 7 (very likely).

\section{$4 \quad$ Results}

Results show that wearing a beard $(M=4.38, S D=.99)$ versus no beard $(M=4.13$, $\mathrm{SD}=.86)$ significantly increases a candidate's perceived expertise, $\mathrm{F}(1,215)=4.01$, $\mathrm{p}<.05$. Using Hayes' (2013) method for assessing mediation and moderated mediation effects, this perceived increase in expertise is in turn shown to be significantly related to the likeliness to be invited for a job interview, such that perceived expertise mediates the relationship between beardedness and job interview invitation intentions $\left(\mathrm{b}^{*}=.133,95 \% \mathrm{CI}=.016-.290\right)$. Moreover, findings suggest that this effect is particularly conducive for jobs that are associated with expertise $\left(b^{*}=.130,95 \% \mathrm{CI}=\right.$ .015 - .288). For jobs that are related to attractiveness and trust, beardedness did not significantly improve perceived expertise and invitation prospects.

\section{Discussion}

Our study contributes to research and practice in the following ways. First, although prior research shows that SNSs are increasingly popular recruitment tools, there has 
been very little empirical research into effective personal branding of job candidates on SNSs [14]. Second, in stark contrast to the attention that Facebook has received from marketing and computer-mediated communication scholars, very little research has been dedicated to professional SNSs such as LinkedIn (cf. 1). Third, from a practical perspective, for jobs seekers today, it is important to know which visual cues in an online profile picture can help create positive impressions on employers, and how these self presentation mechanisms work in relation to different job categories. For instance, depending on the type of job one aims for, it may be wise or unwise to wear a colorful shirt, put on a bow tie - or grow a beard.

A limitation of this study with respect to its external validity relates to the cultural context. For instance, studies in the United States have found that in terms of attractiveness, females preferred men to be clean shaven [5], while studies conducted in Europe indicated that bearded men are perceived as more masculine and attractive [2]. Although Barber (2001) suggests that the biological message that wearing a beard is not bound by history and traverses cultural boundaries, especially in the Western hemisphere, future research should take a more formative approach and investigate whether the results also hold in different cultural contexts, and with different types of beards. Wearing a long beard in, for instance, India, unquestionably conveys a different meaning than wearing a long beard in this study's focal country, the Netherlands. Furthermore, as the implications of this research are restricted to the male gender, we encourage future research to focus on the female equivalent of beardedness. According Terry and Krantz (1993), glasses may have a similar effect on the perceived expertise of females, as do beards for males.

In conclusion, based on this research's findings, we advise those who pursue an academic career to question whether it is wise to shave. Getting rid of your Gillettes may open the door to the job of your dreams!

\section{References}

1. Arnold, T.C., Rynes, S.L.: Recruitment and job choice research: Same as it ever was? In: Schmitt, N.W., Highhouse, S., Weiner, I.B. (eds.) Handbook of Psychology, 2nd edn., pp. 104-142. John Wiley \& Sons, Hoboken (2013)

2. Barber, N.: Mustache fashion covaries with a good marriage market for women. Journal of Nonverbal Behavior 25(4), 261-272 (2001)

3. De Souza, A.A.L., Baumgasten, V., Baiao, U., Otta, E.: Perception of men's personal qualities and prospect of employment as a function of facial hair. Psychological Reports 92(1), 201-208 (2003)

4. Dixson, B.J., Brooks, R.C.: The role of facial hair in women's perceptions of men's attractiveness, health, masculinity and parenting abilities. Evolution and Human Behavior 34(3), 236-241 (2013)

5. Feinman, S., Gill, G.W.: Females' response to males' beardedness. Perceptual and Motor Skills 44(2), 533-534 (1977)

6. Fishbein, M., Ajzen, I.: Belief, attitude, intention, and behavior: An introduction to theory and research. Addison-Wesley, Reading (1975)

7. Goffman, E.: The presentation of self in everyday life. Garden City, New York (1959) 
8. Guido, G., Peluso, A.M., Moffa, V.: Beardedness in advertising: Effects on endorsers' credibility and purchase intention. Journal of Marketing Communication 17(1), 37-49 (2011)

9. Hayes, A.F.: Introduction to Mediation, Moderation, and Conditional Process Analysis: A Regression-Based Approach. The Guilford Press, New York (2013)

10. Jackson, W.C., Bendick, M., Romero, H.J.: Employment discrimination against older workers. Journal of Aging \& Social Policy 8(4), 25-46 (1997)

11. Johnston, M.A.: Beard fetish in early modern England. Ashgate Publishing Limited, Farnham (2011)

12. Kamins, M.A.: An investigation into the match-up hypothesis in celebrity advertising:When beauty be only skin deep. Journal of Advertising 19(1), 4-13 (1990)

13. Kluemper, D.H., Rosen, P.A.: Future employment selection methods: evaluating social networking web sites. Journal of Managerial Psychology 24(6), 567-580 (2009)

14. Labrecque, L.I., Markos, E., Milne, G.R.: Online personal branding: Processes, challenges, and implications. Journal of Interactive Marketing 25, 27-50 (2011)

15. Martin, W.W., Gardner, S.N.: The relative effects of eye-gaze and smiling on arousal in asocial situations. The Journal of Psychology 102(2), 253-259 (1979)

16. Misra, S., Beatty, S.E.: Celebrity spokesperson and brand congruence: An assessment of recall and effect. Journal of Business Research 21(2), 159-173 (1990)

17. Muscarella, F., Cunningham, M.R.: The evolutionary significance and social perception of male pattern baldness and facial hair. Ethology and Sociobiology 17(2), 99-117 (1996)

18. Ohanian, R.: Construction and validation of a scale to measure celebrity endorsers' perceived expertise, trustworthiness, and attractiveness. Journal of Advertising 19(3), 39-52 (1990)

19. Petty, R.E., Cacioppo, J.T.: Communication and Persuasion: Central and Peripheral Routes to Attitude Change. Springer, New York (1986)

20. Reed, J., Blunk, E.M.: The influence of facial hair on impression formation. Social Behavior and Personality 18(1), 169-175 (1990)

21. Ruetzler, T., Taylor, J., Reynolds, D., Baker, W.: Understanding perceptions of professional attributes using conjoint analysis. International Journal of Hospitality Management 30(3), 551-557 (2011)

22. Terry, R.L., Krantz, J.H.: Dimensions of trait attributions associated with eyeglasses, men's facial hair, and women's hair length. Journal of Applied Social Psychology 23(21), 1757-1769 (1993)

23. Tobak, S.: Want a great job? Then shave! (September 12, 2012), http: / / www. cbsnews.com/news/want-a-great-job-then-shave/ (accessed February 7, 2014)

24. Walther, J.B.: Computer-mediated communication: Impersonal, interpersonal and hyperpersonal interaction. Communication Research 23(1), 3-43 (1996)

25. Willemsen, L.M., Neijens, P.C., Bronner, F.: The ironic effect of source identification on the perceived credibility of online product reviewers. Journal of Computer-Mediated Communication 18(1), 16-31 (2012)

26. Woodside, A.G., Davenport, J.W.: The effect of salesman similarity and expertise on consumer purchasing behavior. Journal of Marketing Research 11(2), 198-202 (1974) 


\section{Appendix A: Job Vacancies}

Job vacancy: attractiveness

Imagine you are a recruiter. As a recruiter, you are searching for a suitable job candidate for the following open vacancy:

\section{$\underline{\text { Sales Person Fashion Store: }}$}

For an international male fashion brand, we are looking for males to promote our fashion clothes at the entrance of our store in Amsterdam. As a Sales Person, your duty will be to welcome and establish the first contact with our customers.

\section{Requirements:}

- Representative appearance

- Camera and photo friendly

- Aged between 25-35

- Prior experiences in promotion

- Preferably around 1,80-1,90 meters tall

Job vacancy: expertise

Imagine you are a recruiter. As a recruiter, you are searching for a suitable job candidate for the following open vacancy:

\section{$\underline{\text { Architect at an Architectural Firm }}$}

An established architectural firm currently holds a vacant position for an Architect designing new apartment buildings in the North side of Amsterdam. These buildings will rise at the side of the IJ River as a prestigious project where the very upper class of the city is expected to be housed. Candidates will be requested to submit their resume including portfolio to apply for this position.

\section{Requirements:}

- a Master's (or equivalent) degree in Architecture

- 7-10 years of experience with architectural design; conceptual thinker

- Expertise in leading residential property development projects from initial design process to property transfer

- Comprehensive technical knowledge of residential building codes

- Computer skills: experience required in 3ds Max and AutoCAD 
Job vacancy: trustworthiness

Imagine you are a recruiter. As a recruiter, you are searching for a suitable job candidate for the following open vacancy:

\section{$\underline{\text { Back Office Cashier at a Bank }}$}

For a banking company we are looking for a cashier to work in the back office. As a Back Office Cashier you are responsible for the daily operations and financial security procedures of this bank.

Requirements:

- You must be self-disciplined and reliable

- You will possess two or more years of back office cashier experience at a bank or comparable environment

- You will count money in cash drawers at the beginning of shifts to ensure that amounts are correct and that there is

- adequate change

- You will ensure safe keeping records are all up to date

- You will be trusted with confidential client information 